\title{
Control and Analysis of a Magnetorheological Energy Absorber for both Shock and Vibration
}

\author{
Xian-Xu Bai \\ Precision and Intelligence Laboratory (P\&ILab), Key Lab for Optoelectronic Technology and Systems, Ministry of \\ Education, College of Optoelectronic Engineering, Chongqing University, Chongqing, 400044, China \\ Laboratory for Adaptive Structures and Intelligent Systems (LASIS), Department of Vehicle Engineering, Hefei \\ University of Technology, Hefei, 230009, China
}

Norman M. Wereley

Department of Aerospace Engineering, University of Maryland, College Park, MD, 20742, USA

\begin{abstract}
Dai-Hua Wang
Precision and Intelligence Laboratory (P\&ILab), Key Lab for Optoelectronic Technology and Systems, Ministry of Education, College of Optoelectronic Engineering, Chongqing University, Chongqing, 400044, China
\end{abstract}

\begin{abstract}
(Received 1 November 2015; accepted 5 October 2016)
In this paper, the shock and vibration control effectiveness of the systems based on the magnetorheological (MR) energy absorber (EA) with an internal bypass is investigated and compared with a conventional MREA with an identical volume, the MREA with an internal bypass at passive-on state, and a passive EA based systems. The mechanical model of the single-degree-of-freedom (SDOF) shock and vibration control systems using these four EAs is constructed and the governing equation for the SDOF system is derived. A skyhook control algorithm is used to validate the shock and vibration control performance of the systems. The control performances of the systems under shock loads due to vertical impulses (the maximal initial velocity is as high as $10 \mathrm{~m} / \mathrm{s}$ ) and sinusoidal vibrations are evaluated, compared, and analyzed. The research results indicate that compared to the other three systems, the MREA with an internal bypass based system provides much better vibration control performance, and for the vertical shock control, the MREA with an internal bypass based system requires the shortest settling time to reach steady state and needs shortest travelling stroke.
\end{abstract}

\section{INTRODUCTION}

Magnetorheological (MR) fluids, which are a typical "smart material" with reversible, rapid, and continuous rheological properties, have attracted a lot of attention during the past two decades. ${ }^{1,2}$ MR fluid-based actuators and their semi-active control systems are usually employed to absorb or dissipate unwanted energy, such as vibration suppression ${ }^{3-7}$ and highspeed shock mitigation. ${ }^{8-11}$ Figure 1 presents the schematic of a semi-active shock and vibration control system based on MR energy absorbers (MREAs). Figure 1 shows that the shock and vibration excitations to the plant, such as commercial-offthe-shelf equipment, occupants on a seat suspension of a helicopter or a ground vehicle, gun recoil, and even the crashworthiness systems, could be mitigated or controlled by using the semi-active control system based on MREAs. The control performance of this control system is mainly dependent on two key units, as seen from Fig. 1, (i) the system controller and the MREA controller, i.e., the control strategy for the feedback control system, and (ii) the damping force performance of the MREA, including the damping force range, dynamic range, and the constant stroking load velocity range. ${ }^{12}$

MREAs and the theory of MREAs were only proposed for low-speed applications for a long time, such as vibration con-

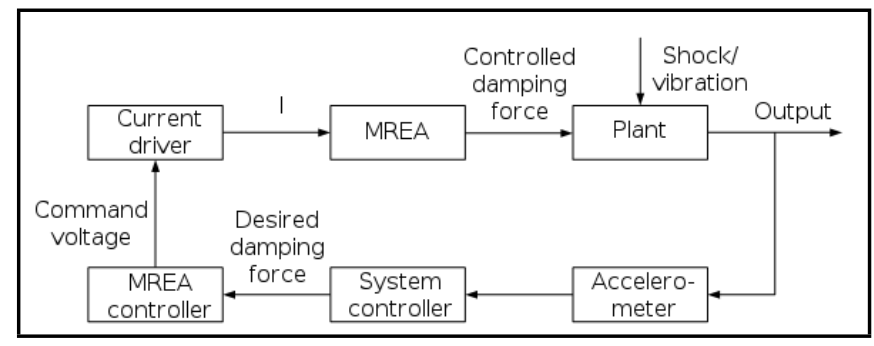

Figure 1. The schematic of a semi-active shock and vibration control system based on MREA.

trol, ${ }^{13-17}$ due to their limited damping force performance, especially the dynamic range. ${ }^{8,11,12}$ The conventional MREAs with bobbin-in-piston could improve its dynamic range by sacrificing the damping force range, ${ }^{12}$ but the efficiency of the magnetic circuit is restricted because of the MR fluid flow gap increment. ${ }^{18}$ Bai et al. proposed a novel MREA with an internal bypass ${ }^{11}$ in order to optimize the damping force performance of the MREA. From their research results, including the finite element analysis (FEA) validation of the principle of the magnetic circuit as well as the experimental tests of the MREA with an internal bypass, the damping force range, the dynamic range, and the constant stroking load velocity range of the MREA can be optimized significantly by an "internal 


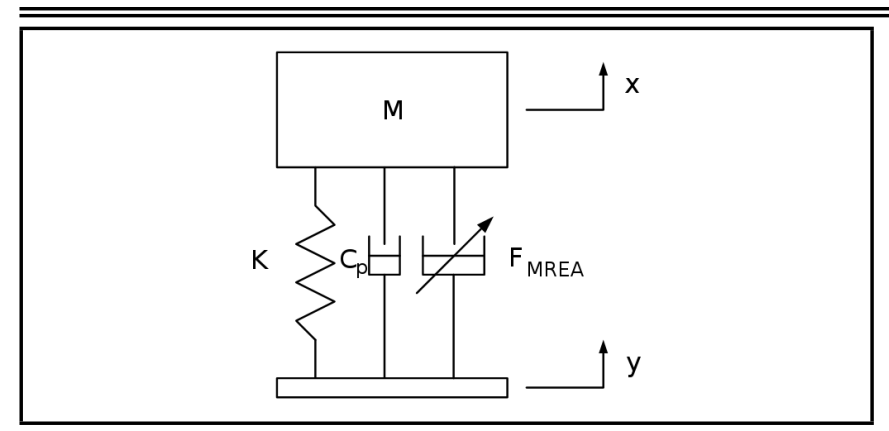

Figure 2. Schematic of SDOF shock and vibration control system.

bypass" concept. The comparison of the MREA with an internal bypass and the conventional MREA with an identical volume and their geometric dimensions are presented in Fig. 11 and listed in Table 1, respectively, in the Appendix. It should be noted that the MREAs have an identical active length and damper cylinder diameter, although the bobbin-in-piston configuration has a much shorter stroke than the MREA with an internal bypass.

In this study, based on an identical semi-active control strategy, i.e., the skyhook control, we will further investigate how the damping force performances of the MREAs affect the shock and vibration control effectiveness. Sequentially, four kinds of single-degree-of-freedom (SDOF) shock and vibration control systems based on EAs are studied, including the semi-active control systems based on the MREA with an internal bypass and a conventional MREA, a passive EA, and an MREA with an internal bypass at passive-on state. A skyhook control algorithm is utilized to validate the shock and vibration control performance of the systems. The control performances of the systems under both shock loads due to vertical impulses and sinusoidal vibrations are evaluated, compared, and analyzed.

\section{THE MAGNETORHEOLOGICAL ACTIVE CONTROL SYSTEM}

\subsection{Modeling of the System}

A SDOF shock and vibration control system based on an MREA and a spring is presented in Fig. 2. The MREA could provide a passive damping force and a field-dependent controlled damping force (FMREA). According to Fig. 2, the dynamic model of the SDOF system can be written as:

$$
M \ddot{x}=-K(x-y)-C_{\mathrm{p}}(\dot{x}-\dot{y})-F_{\mathrm{MREA}} ;
$$

where $M$ is the mass of the payload, $K$ is the stiffness of the coil spring installed parallel to MREA, $C_{\mathrm{p}}$ is the passive damping of the MREA, $x, \dot{x}$, and $\ddot{x}$ are the displacement, velocity, and acceleration of the payload, respectively, and $y$ and $\dot{y}$ are the displacement and velocity of the base excitation, respectively.

The initial conditions are given by:

$$
x_{t=0}=0 \quad \text { and } \quad \dot{x}_{t=0}=0 \text {; }
$$

where $t$ is the time.
It should be noted that the yield force of the MREA ( $\left.F_{\text {MREA }}\right)$ is related to the magnitude of the applied current to the MREA and shows a time response of practical application. $F_{\text {MREA }}$ is related to the applied current and can approximately be given by:

$$
F_{\text {MREA }}=\alpha \cdot I^{\beta}
$$

where $I$ is the applied current to the MREA and $\alpha$ and $\beta$ are the coefficients that can be obtained by using parameter identification using the experimental data.

The yield force is modeled as a first-order low pass filter system given by: ${ }^{19}$

$$
\dot{F}_{\text {MREA }}^{*}=-\frac{F_{\text {MREA }}^{*}}{\tau}+\frac{F_{\text {MREA }}}{\tau} ;
$$

where $F_{\text {MREA }}^{*}$ is the filtered yield force, $\tau$ is the time constant of the MREA and is assumed to be $10 \mathrm{~ms}$. The filtered yield force is substituted for the yield force $F_{\text {MREA }}$ and the damping forces of the MREA with an internal bypass and the conventional MREA are obtained from the parameters given in the Appendix and Reference. ${ }^{11}$

\subsection{Semi-Active Control}

The skyhook control algorithm is used to validate the shock and vibration control performance of the semi-active systems. The skyhook control, which was first introduced and studied for semi-active control systems by Karnopp and Crosby, is often used for vehicular primary suspension systems. ${ }^{20,21}$ The governing equation for the skyhook control is written as:

$$
F_{\text {MREA }}=\left\{\begin{array}{lll}
C_{\text {con }} \dot{x} & \text { if } & \dot{x}(\dot{x}-\dot{y}) \geq 0 \\
0 & \text { if } & \dot{x}(\dot{x}-\dot{y})<0
\end{array} ;\right.
$$

where $C_{\text {con }}$ is a damping that is used such that the full damping range of the MREA. According to the skyhook control principle, the damping force of the MREA should be adapted to pull down the payload since the relative velocity through the MREA is positive. However, if the relative velocity is negative, the damping force should push up the payload. Thus, as given by Eq. (5), the SDOF semi-active control system (see Fig. 2), the semi-active skyhook control switches the force onto the desired force when the force and the relative velocity are the same sign and turns the MREA off when they are the opposite sign. Combining Eq. (3), the desired applied current can be obtained. The current driver as shown in Fig. 1 works. The skyhook control emulates the ideal body displacement control configuration of a passive damper "hooked" between the payload and the "sky". 3 The semi-active skyhook control system based on the MREA is always stable as long as the original system is initially stable, instabilities such as control spillover will never be produced.

\section{VALIDATION OF THE SHOCK AND VIBRATION CONTROL SYSTEM}

In order to analyze the performance of the MREA with an internal bypass, the control response of the semi-active control system based on the MREA, as shown in Fig. 2,is evaluated 


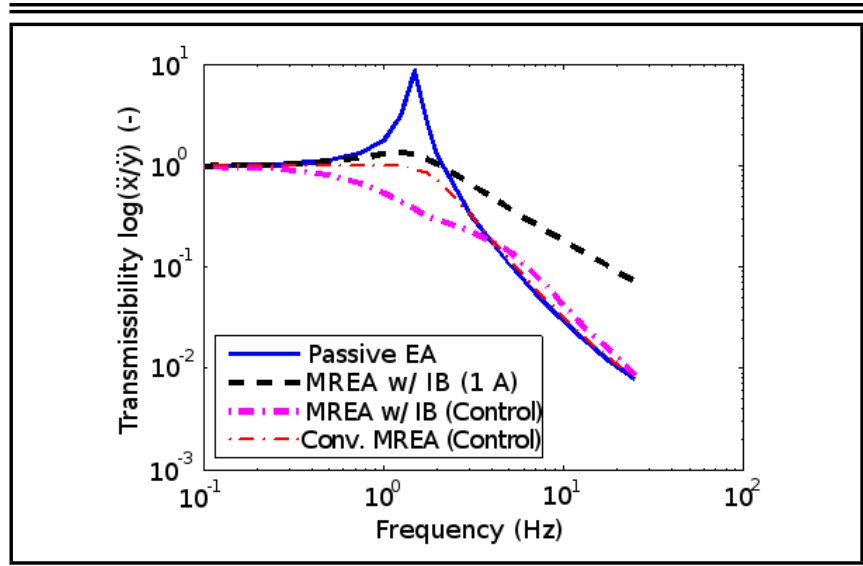

Figure 3. Transmissibility of the payload in the SDOF shock and vibration control system to sinusoidal vibration excitation.

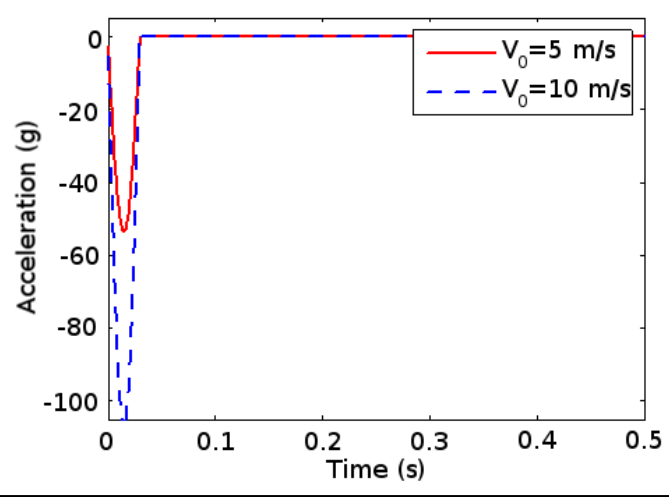

Figure 4. Half-sine wave shock loads with various initial velocities to the base of the SDOF shock and vibration control system.

against two different representative loads from the bases, sinusoidal vibration and vertical shock, and is compared with control systems based on passive EA and conventional MREA. It is noted that the passive dampings $\left(C_{\mathrm{p}}\right)$ of the passive EA, conventional MREA, and the MREA with an internal bypass are kept identical. The parameters of the system are: $M=120 \mathrm{~kg}$, $K=10.659 \mathrm{kN} / \mathrm{m}, C_{\mathrm{p}}=131 \mathrm{Ns} / \mathrm{m}$, and $\left(F_{\text {MREA }}\right)_{\max }=4 \mathrm{kN}$. As for the engineering applications, the fail-safe performance of the actuator is particularly significant for the systems (especially for high-speed applications). The MREA with an internal bypass at passive-on state (i.e., fail-safe performance), designed to realize the damping force performance of a conventional passive damper for both shock and vibration control, is considered. The fail-safe performance of the MREA could be realized by employing a permanent magnet with a moderate magnetic field strength inner-set in the magnetic circuit of the MR fluids path. ${ }^{22}$

\subsection{Vibration Control Performance}

Figure 3 presents the theoretical simulation results of the transmissibility of the payload to a sinusoidal vibration load with an amplitude of $15.24 \mathrm{~mm}$ based on the SDOF system, as shown in Fig. 2. The transmissibility is defined by the ratio of the estimated steady amplitude of the response acceleration to the excitation one. As seen in Fig. 3, in a frequency range of $0-1.5 \sqrt{2} \mathrm{~Hz}$, the vibration control performance of the

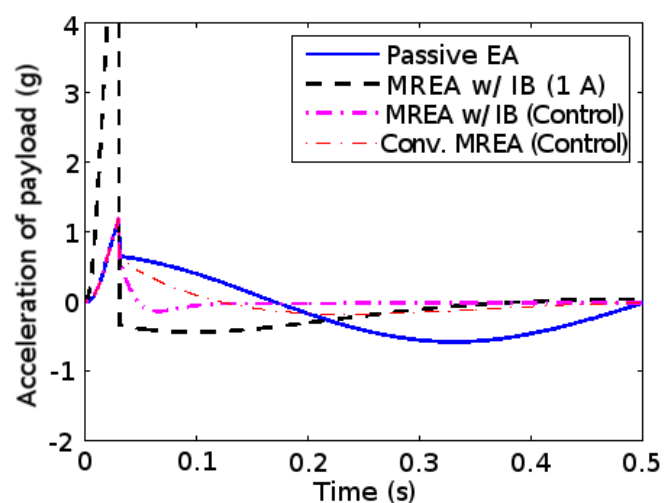

(a)

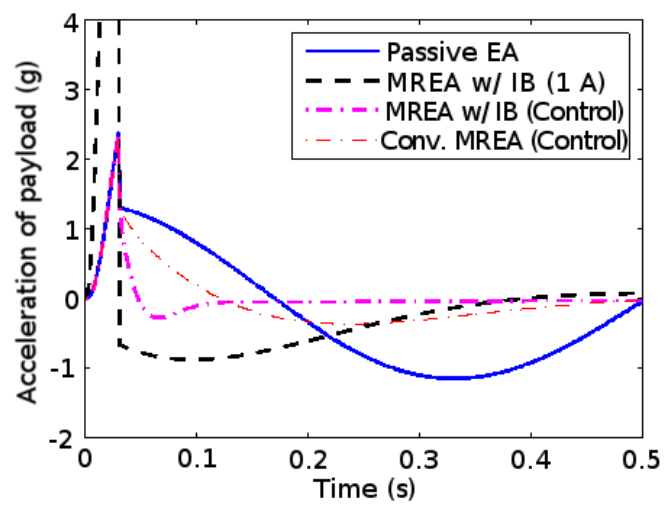

(b)

Figure 5. Acceleration of the payload when the SDOF shock and vibration control system is under half-sine wave shock loads with various initial velocities: (a) $V_{0}=5 \mathrm{~m} / \mathrm{s}$ and (b) $V_{0}=10 \mathrm{~m} / \mathrm{s}$.

SDOF system based on the passive EA is the worst case. Especially at the resonance frequency of $1.5 \mathrm{~Hz}$, the vibration magnitude of the base excitation is amplified nearly 10 times by the passive system. The SDOF semi-active systems based on the MREAs have a much better vibration control performance, as shown in Fig. 3. The SDOF semi-active system based on the MREA with an internal bypass provides the best vibration control results in the frequency range of $0-4 \mathrm{~Hz}$. The control performance of the conventional MREA based SDOF semiactive system is much better than the passive results, but not as good as that of the SDOF system based on the MREA with an internal bypass, because the damping force range, the dynamic range, and the constant stroking load velocity range of the conventional MREA are much smaller than those of the MREA with an internal bypass. ${ }^{11}$ The MREA with an internal bypass at passive-on state, i.e., $1 \mathrm{~A}$ constant applied current, is seen as a fail-safe state to provide a passive dampers damping force performance. At this state, the vibration control result is also presented in Fig. 3 and is better than that of the passive EA when the frequency of the base excitation is lower than $1.5 \sqrt{2} \mathrm{~Hz}$. However, for the frequency over $1.5 \sqrt{2} \mathrm{~Hz}$, it is the worst case. As aforementioned, the MREA with an internal bypass shows better vibration attenuation performance over most significant frequency range as compared with the passive EA, the MREA with an internal bypass at passive-on state, and the conventional MREA. 


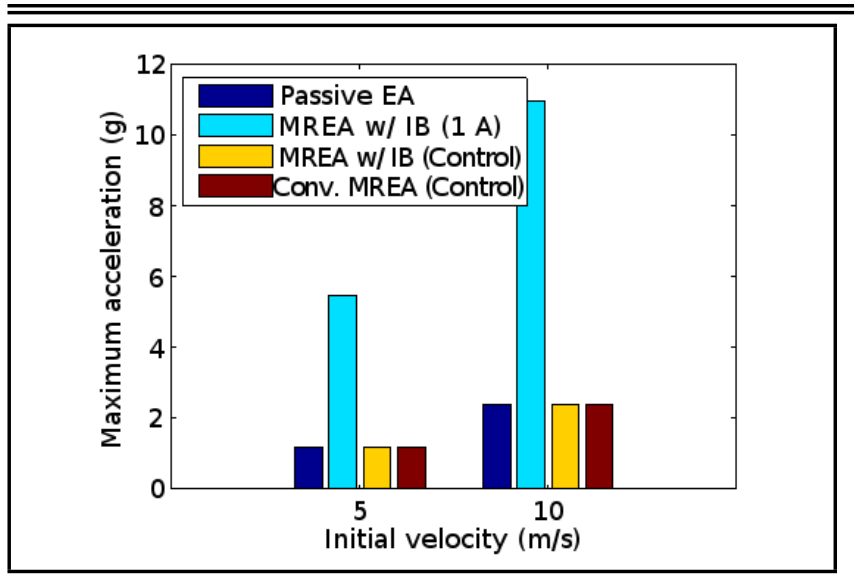

Figure 6. Maximum acceleration of the payload when the SDOF shock and vibration control system is under half-sine wave shock loads with various initial velocities.

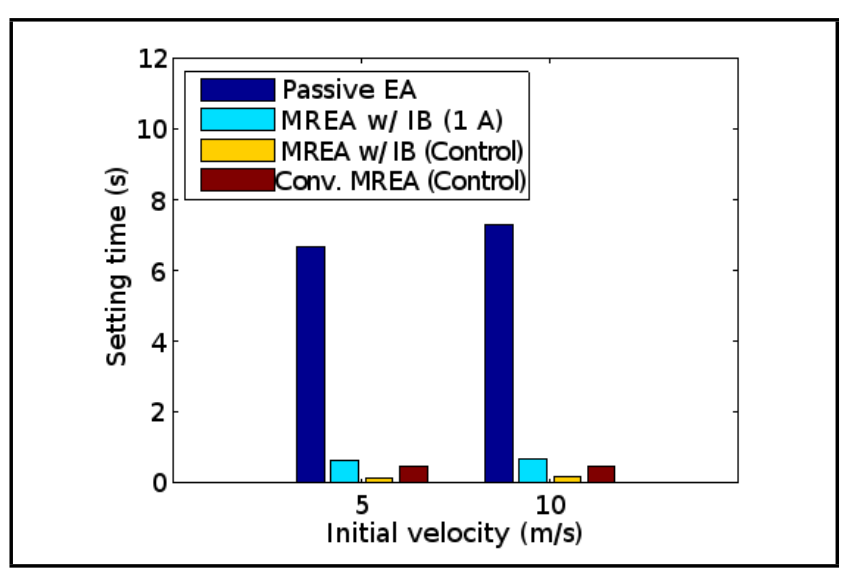

Figure 7. Settling time of the SDOF shock and vibration control system when under half-sine wave shock loads with various initial velocities.

\subsection{Shock Control Performance}

To simulate a practical vertical shock, a half-sine wave with a duration of $30 \mathrm{~ms}$ is used in this study. The displacement excitation to the base of the SDOF system is defined as:

$$
y=\left\{\begin{array}{ll}
\frac{v_{0} t_{s}}{\pi} \sin \frac{\pi t}{t_{s}} & \text { if } 0 \leq t \leq t_{s} \\
0 & \text { if } t>t_{s}
\end{array} ;\right.
$$

where $V_{0}$ is the initial velocity of the vertical shock load; $t_{s}$ is the time duration.

Based on Eq. (6), Fig. 4 presents the half-sine wave shock loads to the base of the SDOF system in term of acceleration, when the initial velocities are $5 \mathrm{~m} / \mathrm{s}$ and $10 \mathrm{~m} / \mathrm{s}$. As seen from Fig. 4, as the shock duration is as short as $30 \mathrm{~ms}$, the acceleration of the base excitation is as high as $-50 \mathrm{~g}$ for an initial velocity of $5 \mathrm{~m} / \mathrm{s}$ and over $-100 \mathrm{~g}$ for an initial velocity of $10 \mathrm{~m} / \mathrm{s}$.

Figures 5 and 6 present the shock response of the payload in profiles of acceleration and the maximum acceleration of the payload, respectively. Figures 5 and 6 present the worst shock control performance provided by the passive system based on the MREA with an internal bypass applied with 1 A constant current, because of the large and uncontrollable damping force of the MREA with an internal bypass at passive-on state. For the other three cases, the passive EA based system, semi-active

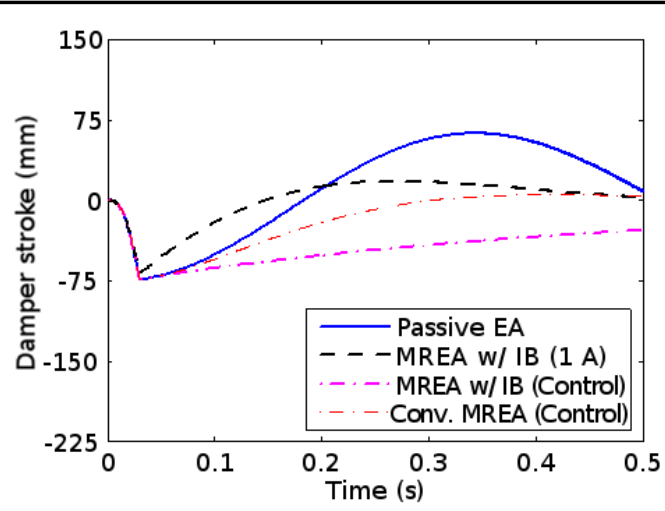

(a)

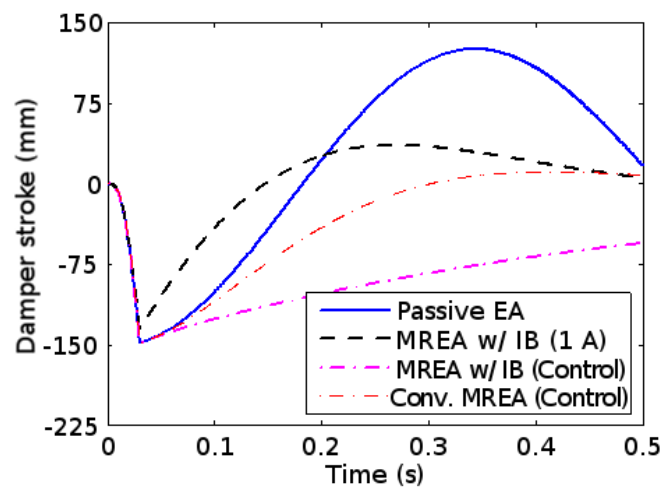

(b)

Figure 8. Strokes of the EAs when the SDOF shock and vibration control system is under half-sine wave shock loads with various initial velocities: (a) $V_{0}=5 \mathrm{~m} / \mathrm{s}$ and (b) $V_{0}=10 \mathrm{~m} / \mathrm{s}$.

control systems with the MREA with an internal bypass and the conventional MREA under skyhook control, the maximum accelerations of the payload are nearly the same. As presented in Figs. 5(a) and 5(b), for these four systems, the time durations of the payload achieving a steady state are obviously different. As the shock initial velocity increases, the corresponding acceleration of the payload increases.

Figure 7 presents a detailed settling time for all of these four systems. Figures 8 and 9 show the strokes of the EAs and the ranges of traveling strokes, respectively. As seen in Figs. 7, 8(a) and 8(b), the settling time and strokes required to dissipate the kinetic energy increases as the initial velocity increases. The passive EA requires the longest time duration and longest stroke requirement to reach steady state. The system based on the MREA with an internal bypass at passive-on state provides better results, a shorter settling time, and a shorter stroke requirement, thanks to its large controllable damping force range. The systems based on the MREA with an internal bypass and the conventional MREA under the skyhook control present even shorter stroke and shorter time to reach steady state. Among these four systems, the system based on the MREA with an internal bypass under skyhook control shows the shortest stroke requirement and settling time to reach steady state, as shown in Figs. 7 and 8. From Fig. 9, for both initial velocities of $5 \mathrm{~m} / \mathrm{s}$ and $10 \mathrm{~m} / \mathrm{s}$, the system based on the MREA with an internal bypass under skyhook control requires shortest traveling stroke. Clearly, the passive EA based system needs the longest EA stroke. If the stroke achieved for 


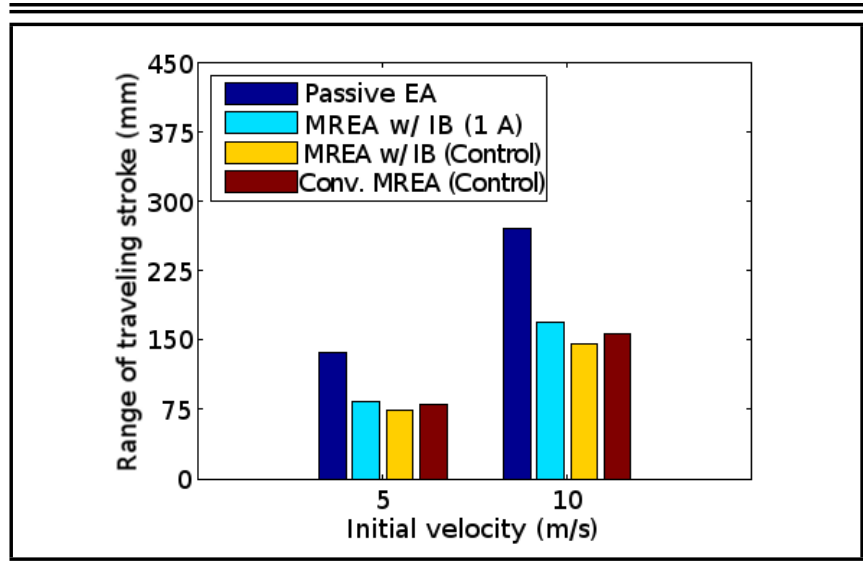

Figure 9. Ranges of the travelling stroke when the SDOF shock and vibration control system is under half-sine wave shock loads with various initial velocities.

the MREA with an internal bypass is used in all cases of the shock control systems in this study, end-stop impact occurs for the other three systems. In other words, the desired "soft landing" 23,24 cannot be achieved. In this study, the settling time is defined by the end time when the payload vibration reaches a steady state evaluated by the ratio of the acceleration response of the payload to the peak excitation acceleration. The ratio should be smaller than $0.05 \%$.

Figures 10(a) and 10(b) show the control damping forces of the MREAs. As shown in Fig. 10, since the controllable damping force of the conventional MREA is much smaller than that of the MREA with an internal bypass,${ }^{11}$ the peak control damping force of the conventional MREA is much smaller than that of the MREA with an internal bypass. Before the first around $0.03 \mathrm{~s}$, there is no damping force response of the both MREAs, which is because of the specific characteristic of skyhook control algorithm as given by Eq. (6) (here condition $\dot{x}(\dot{x}-\dot{y})<0$ is true). When the shock initially happens, we see that the control damping force of the MREA responses better at the beginning to slow down the impact. However, the skyhook control algorithm fails to realize this objective. Hence, a more suitable control algorithm for the shock mitigation control systems employing MREAs should be studied to further improve the control performance.

\section{CONCLUSION}

The theoretical analysis and the prototype testing of the MREA with an internal bypass show that the controllable damping force performance is much better than that of the conventional MREA with an identical volume, although the damper stroke of the conventional MREA is extremely short. This paper aimed to verify the feasibility and capability of MREA with an internal bypass to both the shock and vibration control systems. It compared the control effectiveness of the MREA with an internal bypass with the conventional MREA, an MREA with an internal bypass at passive-on state (i.e., the fail-safe behavior), and passive EA to the shock and vibration control systems. The mechanical model of a SDOF shock and vibration control system using the four EAs was constructed and the governing equation for the SDOF system was derived.

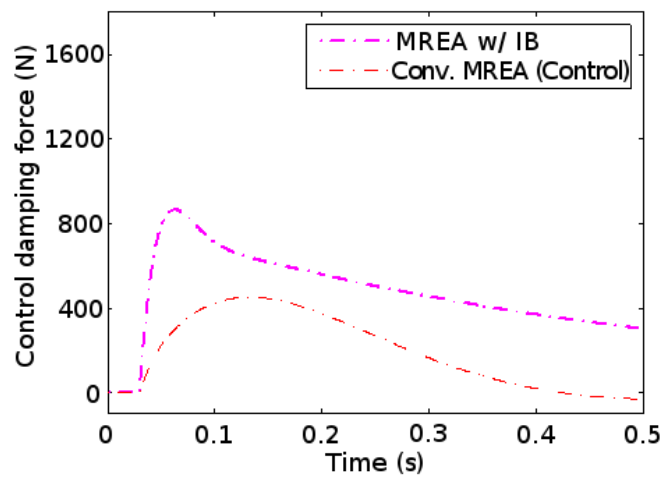

(a)

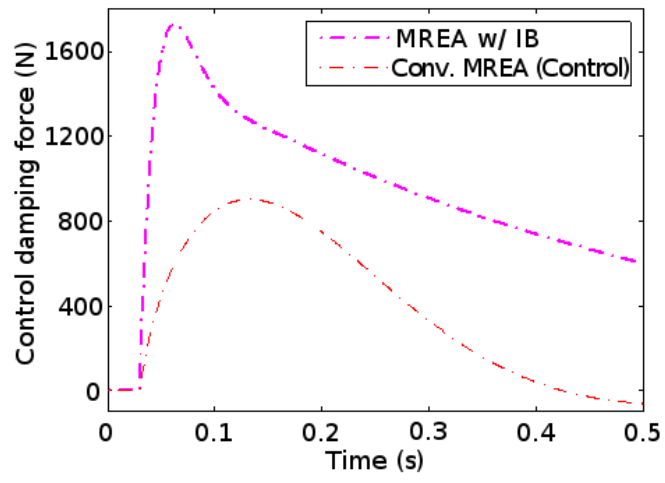

(b)

Figure 10. Control damping forces of the MREAs when the SDOF shock and vibration control system is under half-sine wave shock loads with various initial velocities: (a) $V_{0}=5 \mathrm{~m} / \mathrm{s}$ and (b) $V_{0}=10 \mathrm{~m} / \mathrm{s}$.

A skyhook control algorithm was utilized to validate the shock and vibration control performance of the systems. The control performances of the systems under both shock loads due to vertical impulses with maximal initial velocity of as high as $10 \mathrm{~m} / \mathrm{s}$ and sinusoidal vibrations were evaluated, compared, and analyzed.

According to the research results, concluding remarks can be drawn as follows:

1. The MREA with an internal bypass based system provides a much better vibration control performance than the systems based on the passive EA, the MREA with an internal bypass at passive-on state, and the conventional MREA with an identical volume. The passive-on state of the MREA with an internal bypass can be used as a fail-safe mode for vibration control, in consideration of the failure of the system controller and MREA controller. At the passive-on state, the vibration control performance is better than that of the passive EA based system at low excitation frequency area.

2. For the vertical shock control, the MREA with an internal bypass based system shows dominant shock control performance, including the shortest settling time to reach steady state, and the shortest travelling stroke, as compared to the systems based on the passive EA, the MREA with an internal bypass at passive-on state, and the conventional MREA. The MREA with an internal by- 
pass would be the most promising actuator to realize "soft landing."

3. The skyhook control algorithm is not a perfect control strategy for semi-active shock mitigation control systems based on MREAs and the control strategies for shock control is worth of further investigation.

The "internal bypass" concept for MREA design to improve the damping force performance and the feasibility and capability for the system based on the MREA with an internal bypass are validated. This new MREA design concept would be one of most promising ways to enlarge the MREA applications, especially for high-speed shock control.

\section{ACKNOWLEDGEMENTS}

The authors wish to acknowledge the National Natural Science Foundation of China (Grant No. 51305114), and Key Research and Development Projects of Anhui Province and Equipment Pre-Research Foundation of China during the 13th Five-Year Plan Period (Grant No. 6140240040101), for their support of this research.

\section{REFERENCES}

1 Magnetorheological fluids: materials, characteristics, and devices, Journal of Intelligent Material Systems and Structures, 7 (2), 123-130, (1996). http://dx.doi.org/10.1177/1045389X9600700201

2 Sherman, S., Becnel, A. C., and Wereley, N. M. Relating mason number to Bingham number in magnetorheological fluids, Journal of Magnetics and Magnetic Materials, 380 (1), 98-104, (2015). http://dx.doi.org/10.1016/j.jmmm.2014.11.010

3 Ahmadian, M. and Christopher, A. P. A quarter-car experimental analysis of alternative semiactive control methods, Journal of Intelligent Material Systems and Structures, 11 (6), 604-612 (2000). http://dx.doi.org/10.1106/MR3W5D8W-0LPL-WGUQ

4 Zhu, W. and Rui, X. T. Semiactive Vibration control using a magnetorheological damper and a magnetorheological elastomer based on the Bouc-Wen Model, Shock and Vibration, 405421 (10pp), (2014). http://dx.doi.org/10.1155/2014/405421

5 Shin, Y. J., You, W. H., Hur, H. M., and Park, J. H. H $\infty$ Control of railway vehicle suspension with MR damper using scaled roller rig, Smart Materials and Structures, 23 (9), 95023-95034, (2014). http://dx.doi.org/10.1088/0964$1726 / 23 / 9 / 095023$

6 Motra, G. B. and Chandiramani, N. K. Control of MR damper connected buildings by output feedback, International Journal of Acoustics and Vibration, 19 (4), 240-251, (2014). http://dx.doi.org/10.20855/ijav.2014.19.4356
7 Krishnamoorthy, A. Seismic control of continuous bridges using variable radius friction pendulum systems and viscous fluid dampers, International Journal of Acoustics and Vibration, 20 (1), 24-35, (2015). http://dx.doi.org/10.20855/ijav.2015.20.1365

8 Mao, M., Hu, W., Choi, Y. T., and Wereley, N. M. A magnetorheological damper with bifold valves for shock and vibration mitigation, Journal of Intelligent Material Systems and Structures, 18 (12), 1227-1232, (2007). http://dx.doi.org/10.1177/1045389x07083131

9 Bai, X. X. and Wang, D. H. Shock and vibration control systems using a self-sensing magnetorheological damper, Proceedings of SPIE Conference on Smart Structures/NDE, San Diego, USA, 9057, 905734 (11pp), (2014). http://dx.doi.org/10.1117/12.2045259

10 Mao, M., Hu, W., Choi, Y. T., Wereley, N. M., Brown, A. L., Ulicny, J., and Johnson, N. Nonlinear modeling of magnetorheological energy absorbers under impact conditions, Smart Materials and Structures, 22 (11), 115015 (12pp), (2013). http://dx.doi.org/10.1088/0964-1726/22/11/115015

11 Bai, X. X., Hu, W., and Wereley, N. M. Analysis and testing of an inner bypass magnetorheological damper for shock and vibration mitigation, Proceedings of SPIE Conference on Smart Structures/NDE, San Diego, USA, 8868, 88680Y (18pp), (2013). http://dx.doi.org/10.1117/12.2010001

12 Bai, X. X., Hu, W., and Wereley, N. M. Magnetorheological damper utilizing an inner bypass for ground vehicle suspensions, IEEE Transactions on Magnetics, 49 (7), 3422-3425, (2013). http://dx.doi.org/10.1109/tmag.2013.2241402

13 Spencer, Jr. B., F., Dyke, S. J., Sain, M. K., and Carlson, J. D. Phenomenological model for magnetorheological dampers, Journal of Engineering Mechanics, 123 (230), 230-238, (1997). http://dx.doi.org/10.1061/(asce)07339399(1997)123:3(230)

14 Wang, X. and Gordaninejad, F. Flow analysis of filedcontrollable electro- and magneto-rheological fluids using Herschel-Bulkley Model, Journal of Intelligent Material Systems and Structures, 10 (8), 601-608, (1999). http://dx.doi.org/10.1106/p4fl-11el-yflj-btre

15 Li, W. H., Yao, G. Z., Chen, G., Yeo, S. H., and Yap, F. F. Testing and steady state modeling of a linear MR Damper under sinusoidal loading, Smart Materials and Structures, 13, 95-102, (2000). http://dx.doi.org/10.1088/0964$1726 / 9 / 1 / 310$

16 Xue, X. M., Wu X., Sun Q., and Zhang L. Simulation of the hysteresis model for the MR fluid damper using a hybrid evolutionary algorithm, International Journal of Acoustics and Vibration, 20 (4), 207-219, (2015). http://dx.doi.org/10.20855/ijav.2015.20.4384 
17 Sims, N. D., Holmes, N. J., and Stanway, R. A unified modelling and model updating procedure for electrorheological and magnetorheological vibration dampers, Smart Materials and Structures, 13, 100-121, (2004). http://dx.doi.org/10.1088/0964-1726/13/1/012

18 Bai, X. X., Wang, D. H., and Fu, H. Principle, Modeling, and testing of an annular-radial-duct magnetorheological damper, Sensors and Actuators: A Physical, 201, 302-309, (2013). http://dx.doi.org/10.1016/j.sna.2013.07.028

${ }^{19}$ Choi, Y. T. and Wereley, N. M. Shock isolation system using magnetorheological dampers, Journal of Vibration and Acoustics, 130 (2), 024503 (6pp), (2008). http://dx.doi.org/10.1115/1.2775517

${ }^{20}$ Karnopp, D. C. and Crosby, M. J. System for controlling the transmission of energy between spaced members, U.S. Patent 3,807,678, (1974). http://dx.doi.org/10.1115/1.3438373

${ }^{21}$ Karnopp, D., Crosby, M. J., and Harwood, R. Vibration control using semiactive force generators, Journal of Engineering For Industry, 96 (2), 619-626, (1974). http://dx.doi.org/10.1115/1.3438373

22 Bai, X. X., Wereley, N. M., and Choi, Y. T. Magnetorheological energy absorber with dual concentric annular valves, Journal of Intelligent Material Systems and Structures, 27 (7), 944-958, (2016). http://dx.doi.org/10.1177/1045389x15577659

23 Wereley, N. M., Choi, Y. T., and Singh, H. J. Adaptive energy absorber for drop-induced shock mitigation, Journal of Intelligent Material Systems and Structures, 22 (6), 515519, (2011). http://dx.doi.org/10.1177/1045389x10393767

24 Singh, H. J. and Wereley, N. M. Adaptive magnetorheological shock isolation mounts for drop-induced impacts, Smart Materials and Structures, 22 (12), 122001 (10pp), (2013). http://dx.doi.org/10.1088/0964-1726/22/12/122001

Table 1. The parameters and dimensions of MREAs. ${ }^{11}$

\begin{tabular}{|c|c|c|}
\hline \multirow[b]{2}{*}{ Parameter } & \multicolumn{2}{|c|}{ Symbol/Value } \\
\hline & $\begin{array}{l}\text { MREA with an } \\
\text { internal bypass }\end{array}$ & Conventional MREA \\
\hline Stroke & $s: 150 \mathrm{~mm}$ & $s_{p b}: 30 \mathrm{~mm}$ \\
\hline Radius of piston & $r_{p}: 15 \mathrm{~mm}$ & $r_{p b}: 25.8 \mathrm{~mm}$ \\
\hline Outer radius of inner tube & $r_{i c}: 24 \mathrm{~mm}$ & - \\
\hline $\begin{array}{l}\text { Thickness of MR fluid } \\
\text { flow duct }\end{array}$ & $d: 1.8 \mathrm{~mm}$ & $d_{p b}: 4.45 \mathrm{~mm}$ \\
\hline Radius of piston rod & \multicolumn{2}{|c|}{$r_{p r}: 6 \mathrm{~mm}$} \\
\hline $\begin{array}{l}\text { Outer radius of damper } \\
\text { cylinder }\end{array}$ & \multicolumn{2}{|c|}{$r_{o c}: 30 \mathrm{~mm}$} \\
\hline Active length each stage & \multicolumn{2}{|c|}{$L: 15 \mathrm{~mm}$} \\
\hline MR fluid density & \multicolumn{2}{|c|}{$\rho: 3.02 \times 10^{3} \mathrm{~kg} / \mathrm{m}^{3}$} \\
\hline MR fluid viscosity & \multicolumn{2}{|c|}{$\eta: 0.1 \mathrm{~Pa} \mathrm{~s}$} \\
\hline Roughness of the pipe wall & \multicolumn{2}{|c|}{$\epsilon: 0.0008 \mathrm{~mm}$} \\
\hline $\begin{array}{l}\text { Number of electromagnetic } \\
\text { coil stages }\end{array}$ & \multicolumn{2}{|c|}{$N: 5$} \\
\hline $\begin{array}{c}\text { Turns of electromagnetic } \\
\text { coil of each stage }\end{array}$ & \multicolumn{2}{|c|}{$N_{\text {coil }}: 175$} \\
\hline
\end{tabular}

\section{APPENDIX: COMPARISON OF MREAS}

As seen from Fig. 11 and Table 1, the MREAs have an identical active length and damper cylinder diameter, although the conventional MREA has a much shorter stroke than the MREA with an internal bypass.

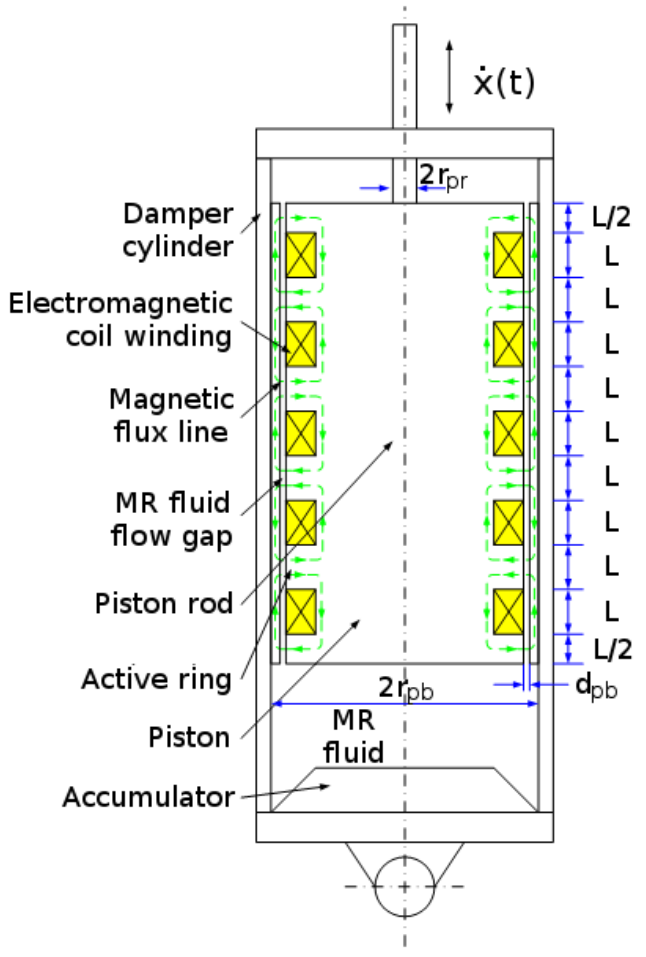

(a)

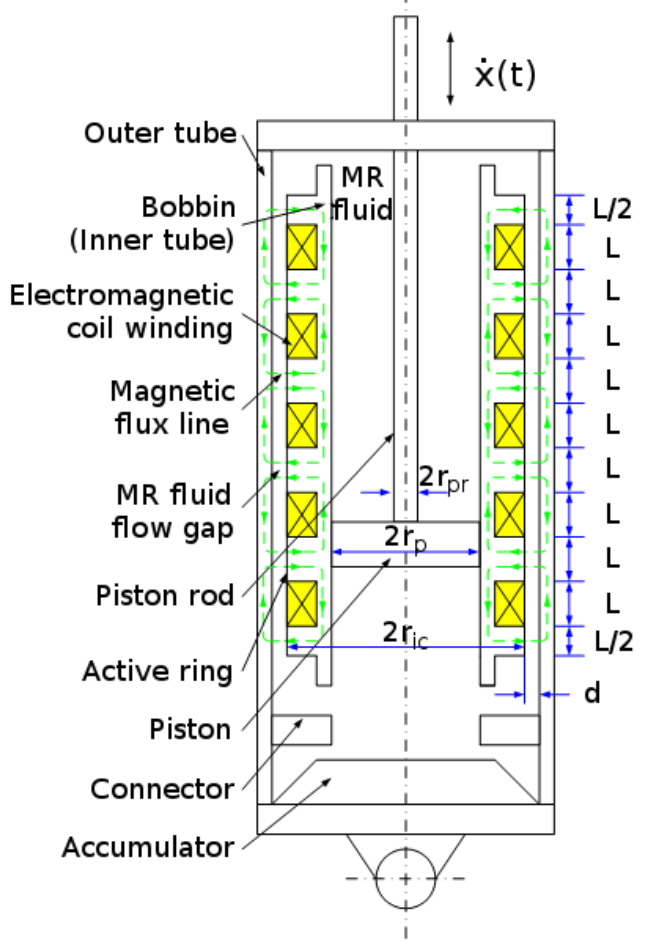

(b)

Figure 11. Schematics of MREAs: ${ }^{11}$ (a) MREA with a conventional bobbinin-piston configuration and (b) MREA with an internal bypass. 